\title{
A study of low birth weight prevalence and risk factors among newborns in a public-hospital at Kilis, Turkey
}

\author{
Hasan Hüseyin Çam ${ }^{1}$, Muazzez Harunoğulları², Yadigar Polat ${ }^{3}$
}

1. Kilis 7 Aralik University Yusuf Serefoglu Faculty of Health Sciences, Department of Nursing..

2. Kilis 7 Aralik University Faculty of Arts and Sciences, Department of Geography

3. Kilis 7 Aralik University Vocational School of Health Services, Department of Medical and Technical Service.

\begin{abstract}
Background: Low birth weight (LBW) is an important indicator of reproductive health and general health status of population.

Objectives: The present study was aimed to estimate the prevalence of low birth weight (LBW), and to investigate the associations between some risk factors and LBW in Syrian refugee and Turkish population in Kilis, Turkey.

Methods: The population of this study constituted of a total of 4379 infants born in Kilis State Hospital in 2016 using a retrospective cross-sectional study design. The data were collected from birth records. The data were analyzed using SPSS version 16.0. Binary logistic regression analysis was performed to identify predictors of low birth weight. Factors with a p-value $<0.05$ were deemed to be statistically significant.

Results: The prevalence of LBW was $6.7 \%$ in all groups. Significant relationships were found between young maternal age, Syrian refugee mother, female infants, cesarean delivery and LBW.

Conclusion: The prevalence of low birth weight in the study area was comparatively lower than that of countrywide figure. Maternal related variables like, maternal age, mother's nationality, and mode of birth (vaginal, cesarean) take after up as well as new-born related variables like gender of the neonate were significantly related with low birth weight.
\end{abstract}

Keywords: Low birth weight, maternal, risk factors, prevalence'

DOI: https://doi.org/10.4314/ahs.v20i2.22

Cite as: Cam HH, Harunoğulları M, Polat $Y$. A study of low birth weight prevalence and risk. factors among newborns in a public-hospital at Kilis, Turkey. Afri Health Sci. 2020; 20(2): 709-714. bttps:// doi.org/10.4314/abs.v20i2.22

\section{Introduction}

Low birth weight (LBW) continues to remain a major public health problem worldwide, especially in the developing countries. The birth weight of an infant is the single most important determinant of its chances of survival, healthy growth, and development ${ }^{1}$. World Health Organization (WHO) defines the low birth weight as weight at birth of less than 2,500 grams (5.5 pounds). According to the epidemiological observations, infants weighing less than 2,500 $\mathrm{g}$ are approximately 20 times more likely to die than heavier infants ${ }^{2}$.

More than 20 million infants worldwide, representing 15.5 percent of all births are born with low birth

\section{Corresponding author:}

Hasan Hüseyin Çam,

Kilis 7 Aralik University Yusuf Serefoglu

Faculty of Health Sciences, Department of Nursing

Email: cam_hasanhuseyin@hotmail.com weight, 95.6 percent of them in developing countries. The level of low birth weight in developing countries (16.5 percent) is more than double in comparison with the level in developed regions $(7 \text { percent })^{2}$. According to the Turkey Demographic and Health Survey report, 10 percent of the births in the last five years prior to 2013 are of LBW (less than 2,500 g). In the Southeastern Anatolia Region, $13.5 \%$ of the infants are reported to be LBW. It was documented that the ratio of LBW infants is lowest in Western Anatolia Region (7.6\%) and highest in Northeast Anatolia Region (17.7\%)

Many and various studies have been performed in order to identify reasons of LBW, documenting that the factors fall into a diversity of socioeconomic, biological, psychological and nutrition-related factors. A number of studies have shown correlates of teenage mother, low maternal weight and height, low maternal education, low calorie intake, maternal anemia, poor antenatal care, maternal smoking, hypertension during pregnancy, hard maternal physical work, genetic syndromes, 
maternal exposure to toxic substances, pregnancy-induced medical ailments, parity, inter pregnancy interval, and bad obstetric history with occurrence of low birth weight infants ${ }^{4,5,6,7}$. The maternal risk factors are biologically and socially interrelated but most of them are variable. We should highlight that all factors might be present in a population at a certain time or interval. The mortality of LBW can be alleviated with the identification of the predominant maternal risk factors in a particular area responsible for LBW1.

According to the Turkish Interior Ministry's Directorate General of Migration Management's 2016 year statistics, there are a total of 2,834,441 registered Syrian migrants in Turkey, corresponding to 3.55 percent of the Turkish population of $79,814,871$. The directorate reported a total of 122,327 Syrians are currently living in the border province of Kilis (ratio to provincial population: $93.50 \%$ ), which has a native population of just $130,825^{8}$. Refugees are a unique subset of migrants who are at increased risk of adverse health outcomes. During pregnancy, refugee women may be exposed to violence, poor health and nutrition, homelessness, and limited access to health care resources ${ }^{9}$. In order to prevent LBW, the predominant risk factors regarding with the LBW are needed to be understood and clarified. Additionally, the interrelationships between maternal, social and cultural factors need to be investigated ${ }^{10}$. In this context, the results obtained along with the present study might be essential to reveal interventions aimed at altering behaviors and other risk variables for low birth weight.

The present study was aimed to estimate the prevalence of low birth weight (LBW), and to investigate the association between some risk factors and LBW in Syrian refugee and Turkish population in Kilis, Turkey.

\section{Methods}

\section{Study design}

This is a cross sectional retrospective epidemiological study has been conducted in a public-hospital at Kilis, Turkey. Kilis State Hospital is the only hospital in the region with a maternity department. Almost all births in Turkey occur in hospitals, in the maternity department. In 2013, $97.2 \%$ of mothers gave birth in hospitals, while much smaller proportions gave birth at home $(2.3 \%)$ or in other settings including births occurring before arrival at hospital $(0.5 \% \text { mothers })^{3}$.

\section{Method/study procedure}

The data were collected from birth records obtained between January 01, 2016 and December 31, 2016. The study population was comprised of hospital files of all women who gave birth in the above-mentioned period and their newborns; the total number of cases was 4379 . No sample was drawn and all singleton live births in Kilis State Hospital, in the study period, were included except those preterm or infants with congenital anomalies. Data was recorded with the assistance of pre-tested \& pre-designed survey. Birth records include the maternal age (years), mother's nationality, gender of infant, mode of birth (vaginal, cesarean), and birth weight (gram). LBW is defined as less than 2,500 grams2. The study protocol was reviewed and approved by the Gaziantep University Clinical Research Ethics Board (Reference Number: 2017/144).

\section{Data analysis}

SPSS 16.0 was used for processing and evaluation of the data. Simple descriptive analysis and Chi-Square test were applied to determine the associated factors of low birth weight. Logistic regression analysis was used to assess relationship between LBW and maternal and infant bio-demographic characteristics. Factors with a P-value $<0.05$ were deemed to be statistically significant.

\section{Results}

The median age of mothers was 25 (range 12-51) with majority of mothers aged 20-34 years. The frequency of Turkish national's mother was $35.8 \%$, while the frequency of Syrian national's mother was $64.2 \%$. The study population comprised 4379 infants, $49.9 \%$ (2185) were males. Of the total number of births there was $3326(76.0 \%)$ vaginally completed and $1053(24.0 \%)$ by cesarean section [Table 1]. 
Table 1 Distribution of mother and baby for some descriptive characteristics

\begin{tabular}{llrl}
\hline Variable & Categories & n & \% \\
\hline Maternal age (years) & $\leq 19$ & 751 & 17.2 \\
(Median: 25) & $20-34$ & 3098 & 70.7 \\
& $\geq 35$ & 530 & 12.1 \\
Mother nationality & Turkish & 1569 & 35.8 \\
& Syrian & 2810 & 64.2 \\
Gender of infant & Male & 2185 & 49.9 \\
& Female & 2194 & 50.1 \\
Mode of birth & & & \\
& Vaginal birth & 3326 & 76.0 \\
Total & Caesarean & 1053 & 24.0 \\
\hline
\end{tabular}

All the variables displayed in the Table 2 were significantly associated with infant birth weight $(\mathrm{p}<0.05)$. The prevalence of LBW was the lowest among mothers aged 20-34 years $(8.5 \%$ for mothers aged $\leq 19$ years, $6.0 \%$ for mothers aged $20-34$ years, and $8.1 \%$ for mothers aged $\geq 35$ years $(p<0.05))$. The prevalence of LBW was found to be higher in Syrian refugee moth- ers (7.7 percent) than in Turkish mothers (4.9 percent) $(\mathrm{p}<0.05)$. Birth weight was influenced by the gender of a child; whereas about 5.8 percent of male infants were born with LBW 7.6 percent of female infants had LBW $(p<0.05)$. LBW prevalence was higher in infants born with cesarean birth ( 8.2 percent) than infants born with vaginal birth $(6.2$ percent $)(\mathrm{p}<0.05)$.

Table 2 Relationship between maternal and infant bio-demographic characteristics and birth weight

\begin{tabular}{|c|c|c|c|c|c|c|c|c|c|}
\hline \multirow{3}{*}{ Variable } & \multirow{3}{*}{ Categories } & & \multicolumn{3}{|c|}{ Low birth weight } & \multicolumn{2}{|c|}{ Total } & \multirow[t]{2}{*}{$\mathbf{X}^{2}$} & \multirow[t]{2}{*}{${ }^{t} \mathbf{p}$} \\
\hline & & \multicolumn{2}{|c|}{$\begin{array}{c}\text { Yes } \\
<2500 \mathrm{~g}\end{array}$} & \multicolumn{2}{|c|}{$\begin{array}{l}\text { No } \\
\geq 2500 \mathrm{~g}\end{array}$} & \multirow[b]{2}{*}{$\mathbf{n}$} & \multirow[b]{2}{*}{$\%$} & & \\
\hline & & $\mathbf{n}$ & $\%$ & $\mathrm{n}$ & $\%$ & & & \multirow{4}{*}{8.092} & \multirow{4}{*}{$<0.05$} \\
\hline \multirow{3}{*}{$\begin{array}{l}\text { Maternal age } \\
\text { (years) }\end{array}$} & $\leq 19$ & 64 & 8.5 & 687 & 91.5 & 751 & 100.0 & & \\
\hline & $20-34$ & 186 & 6.0 & 2912 & 94.0 & 3098 & 100.0 & & \\
\hline & $\geq 35$ & 43 & 8.1 & 487 & 91.9 & 530 & 100.0 & & \\
\hline \multirow{2}{*}{$\begin{array}{l}\text { Mother } \\
\text { nationality }\end{array}$} & Turkish & 77 & 4.9 & 1492 & 95.1 & 1569 & 100.0 & \multirow[t]{2}{*}{12.456} & \multirow[t]{2}{*}{$<0.05$} \\
\hline & Syrian & 216 & 7.7 & 2594 & 92.3 & 2810 & 100.0 & & \\
\hline \multirow{2}{*}{$\begin{array}{l}\text { Gender of } \\
\text { infant }\end{array}$} & Male & 126 & 5.8 & 2059 & 94.2 & 2185 & 100.0 & \multirow[t]{2}{*}{5.969} & \multirow[t]{2}{*}{$<0.05$} \\
\hline & Female & 167 & 7.6 & 2027 & 92.4 & 2194 & 100.0 & & \\
\hline \multirow[t]{3}{*}{ Mode of birth } & Vaginal & 207 & 6.2 & 3119 & 93.8 & 3326 & 100.0 & \multirow[t]{3}{*}{4.838} & \multirow[t]{3}{*}{$<0.05$} \\
\hline & birth & 86 & 8.2 & 967 & 91.8 & 1053 & 100.0 & & \\
\hline & $\begin{array}{l}\text { Caesarean } \\
\text { birth }\end{array}$ & & & & & & & & \\
\hline Total & & 293 & 6.7 & 4086 & 93.3 & 4379 & 100.0 & & \\
\hline
\end{tabular}

"Chi-square test 
A binary logistic regression shows that mothers who were in the age group of less than 19 years were more likely to deliver LBW infants than those mothers in the age group of 20-34 years (OR: 1.42; 95\% CI: 1.05-1.92). Syrian refugee mothers were significantly more likely to be LBW relative to Turkish mothers (OR: 1.67, 95\% CI:
1.26-2.19). Female infants were significantly more likely to be LBW relative to male infants (OR: 1.33, 95\% CI: 1.05-1.70). Delivery using lower segment caesarian section was found to have more risk in developing LBW compared to infants delivered via vaginal delivery (OR: 1.52, 95\% CI: 1.16-2.00) [Table 3].

Table 3 Binary logistic regression analysis of low birth weight risk factors

\begin{tabular}{|c|c|c|c|c|c|c|}
\hline \multirow[t]{2}{*}{ Variable $(n=338)$} & \multirow[t]{2}{*}{ Categories } & \multirow[t]{2}{*}{ B } & \multirow[t]{2}{*}{$\mathbf{p}$} & \multirow{2}{*}{$\begin{array}{l}\text { Odds } \\
\text { ratio }\end{array}$} & \multicolumn{2}{|c|}{$95 \%$ CI } \\
\hline & & & & & Lower & Upper \\
\hline \multirow{3}{*}{$\begin{array}{l}\text { Maternal } \\
\text { age(years) }\end{array}$} & $\leq 19$ & 0.352 & 0.022 & 1.423 & 1.052 & 1.923 \\
\hline & $20-34^{+}$ & - & - & - & - & - \\
\hline & $\geq 35$ & 0.061 & 0.772 & 1.063 & 0.704 & 1.605 \\
\hline \multirow{2}{*}{$\begin{array}{l}\text { Mother } \\
\text { nationality }\end{array}$} & Turkish $^{+}$ & - & - & - & - & - \\
\hline & Syrian & 0.513 & 0.000 & 1.670 & 1.269 & 2.196 \\
\hline \multirow[t]{2}{*}{ Gender of infant } & Male $^{+}$ & - & - & - & - & - \\
\hline & Female & 0.290 & 0.018 & 1.337 & 1.051 & 1.700 \\
\hline \multirow{2}{*}{ Mode of birth } & Vaginal & - & - & - & - & - \\
\hline & $\begin{array}{l}\text { birth }^{+} \\
\text {Caesarean } \\
\text { birth }\end{array}$ & 0.423 & 0.002 & 1.527 & 1.165 & 2.000 \\
\hline Constant & & 1.782 & 0.000 & 5.945 & & \\
\hline
\end{tabular}

${ }^{+}$Reference group

\section{Discussion}

In our study, the percentage of LBW infants was found to be $6.7 \%$ in all groups and this value appears to be at the level of developed regions $(7.0 \%)^{2}$. This finding is inconsistent with that of the national figure which is $10.0 \% 0^{3}$. This difference might be due to the difference in sample size, study setting, delivery site, and types of health facilities, as this study is carried out only among the neonate delivered in one center located in Kilis Province, while the study at national levels included the neonate delivered in multicentre and multiple region. Another possible reason for lower prevalence of low birth weight in our study area could be due to unreported home deliveries.

In this study, the percentage of LBW in infants born from young mothers was higher than that of mothers who gave birth in middle and advanced age. This result may be clarified by that the younger age $\leq 19$ years tended to be unmarried, still in high school, unplanned pregnancy and they too have the problems of biological immaturity concomitant with poor maternal selfcare and insufficient nutrition ${ }^{11}$. Similarly, other studies have also found that infants born from mothers under the age of 19 had a high risk of being $\mathrm{LBW}^{1,10,11,12,13,14,15}$. But this result is in contrast to a study done in India, there was no significant relationship between maternal age and $\mathrm{LBW}^{16}$.

In our study, the percentage of LBW in Syrian refugees was significantly higher than the Turkish. Similarly, in a study conducted in Pakistan, the percentage of LBW was 2.5 times higher in Afghan refugees than in local populations ${ }^{12}$. Likewise, in a study conducted in Hong Kong, the percentage of LBW in Vietnamese refugees was twice as high as Chinese ${ }^{17}$. This can be attributed to the fact that refugee women are exposed to homelessness, malnutrition and limited access to health services during pregnancy.

In a study conducted in Nigeria, it has been reported that female infants are more likely to have LBW than male infants15. Similarly, in a study conducted in Northwest Ethiopia, female infants were found to have lower birth weights than male infants ${ }^{18}$. Similar to the findings of other studies in our study, the percentage of LBW in female infants was higher than that of male infants. The birth weight of male infants is generally higher than fe- 
male infants. This difference starts after 28 weeks of gestation. Although the exact mechanism impacting the difference in birth weight is unknown, it might be due to androgen activities or the $\mathrm{Y}$ chromosome that carries genetic material for fetal growth. As a result, male infants could have higher intrauterine growth and birth weight than their female counterparts ${ }^{19}$.

In our study, the percentage of LBW in infants born by caesarean section was significantly higher than that of infants born by vaginal delivery. In a study conducted in Malaysia, giving birth using lower segment caesarean section (LSCS) was associated with a higher risk of LBW in infants, compared to vaginal births5. But this result is in contrast to a study done in India, a negative relationship was found between cesarean birth and LBW 1. In other studies, conducted in India and Nigeria, there was no significant relationship between cesarean birth and $\mathrm{LBW}^{20,21}$. However, this association should be interpreted with caution cases. They may need to undergone emergency LSCS due to threatened maternal condition but still in premature gestation such as severe pre-eclampsia, eclampsia and bleeding placenta praevia5.

There are some limitations to this study. Firstly, there are too few factors such as other socio demographic characteristic such as paternal weight, maternal education level, smoking status of parents, drug ingestion and occupation that may have impact for LBW newborn children cannot be included in this study due to lacking of information. Secondly, births outside the hospital were not included in the study, and therefore it was not possible to generalize the results to a particular population as compared to population based studies.

In conclusion, significant association was found between young maternal age, Syrian refugee mother, female infants, cesarean delivery and LBW. Improving a mother's information of and practice for a healthy pregnancy ought to be emphasized to invert these LBW trends. Our data highlights an imperative need to devise interventions to reduce adverse birth outcomes for pregnancies of teenagers. Health specialists ought to encourage young mothers to go to focused antenatal care as recommended by Ministry of Health of Turkey. A specialized maternal office centre that's friendly for adolescent/teenage mothers is advisable so as to improve on completion rates and handle high hazard pregnancies. Further detailed study on Syrian refugee outcomes is recommended to understand the main causes of LBW compared to Turkish mothers. An awareness of the likely health issues in this group of women will enable health care administrations to address the refugees' particular health needs and ensure maternal and fetal well-being. Identification of high-risk mothers and early detection and administration of the risk factors would decrease frequency of low birth weight and related short-term and long-term consequences.

\section{References}

1. Bendhari ML, Haralkar SJ. Study of maternal risk factors for low birth weight neonates: A case-control study. Int J Med Sci Public Health. 2015; 4:987-990.

2. United Nations Children's Fund and World Health Organization. Low Birthweight: Country, regional and global estimates. UNICEF, Editorial and Publications Section Division of Communication, New York, 2004. www.who.int/iris/handle/10665/43184 access date 3.05.2017

3. Hacettepe University Institute of Population Studies. 2013 Turkey Demographic and Health Survey. Apple Technical Printing Typography, Ankara, Turkey, 2014. http://www.hips.hacettepe.edu.tr/tnsa2013/ access date 12.05.2017

4. Veloso HJ, da Silva AA, Bettiol H, Goldani MZ, Filho FL, Simões VM, Batista RF, Barbieri MA. Low birth weight in SãoLuís, North eastern Brazil: trends and associated factors. BMC Pregnancy Childbirth. 2014; 14:155. 5. Sutan R, Mohtar M, Mahat A, Tamil A. Determinant of Low Birth Weight Infants: A Matched Case Control Study. Open Journal of Preventive Medicine. 2014; 4:91-99.

6. Anjum F, Javed T, Afzal MF, Sheikh GA. Maternal Risk Factors Associated with Low Birth Weight: A Case Control Study. Annals. 2011; 17(3):223-228.

7. Nayak RK, Metgud CS, Mallapur MD, Naik AN. Prevalence of Low Birth Weight at Primary Health Center of North Karnataka. Int J Pharm Med Bio Sci. 2013; 2(1):1-4.

8. The Republic of Turkey Ministry Of Interior Directorate General Of Migration Management. 2016 Turkey Migration Report, Publications Of The General Directorate Of Migration Administration, Ankara, Turkey, 2017. https://www.goc.gov.tr/files/files/2016_yiik_ goc_raporu_haziran.pdf access date 12.05.2017

9. Kandasamy T, Cherniak R, Shah R, Yudin MH, Spitzer R. Obstetric risks and outcomes of refugee women at a single centre in Toronto. J Obstet Gynaecol Can. 2014; 36(4):296-302.

10. Demelash H, Motbainor A, Nigatu D, Gashaw K, Melese A. Risk factors for low birth weight in Bale zone hospitals, South-East Ethiopia: a case-control study. BMC Pregnancy Childbirth. 2015; 15:264. 
11. Tantayakom C, Prechapanich J. Risk of Low Birth Weight Infants from Adolescent Mothers: Review Case Study in Siriraj Hospital. Thai Journal of Obstetrics and Gynaecology. 2008; 16(2):103-108.

12. Badshah S, Mason L, McKelvie K, Payne R, Lisboa PJ. Risk factors for low birthweight in the public-hospitals at Peshawar, NWFP-Pakistan. BMC Public Health. 2008; 8:197.

13. Joshi HS, Srivastava PC, Agnihotri AK, Joshi MC, Chandra S, Mahajan V. Risk Factors for Low Birth Weight (LBW) Babies and its Medico-Legal Significance. J Indian Acad Forensic Med. 2010; 32(3):212-215.

14. Viengsakhone L, Yoshida Y, Harun-Or-Rashid M, Sakamoto J. Factors affecting low birth weight at four central hospitals in Vientiane, Lao PDR. Nagoya J Med Sci. 2010; 72(1-2):51-58.

15. Isiugo-Abanihe UC, Oke OA. Maternal and environmental factors influencing infant birth weight in Ibadan, Nigeria. African Population Studies. 2011; 5(2):250-266.

16. Paramita S, Sharma N, Benjamin AI. Risk factors for low birth weight: a case control study in Ludhiana, Punjab. IJMCH. 2009; 11:1-4.
17. King PA, Duthie SJ, Li DF, Ma HK. Obstetric outcome among Vietnamese refugees in Hong Kong: an age-matched case-controlled study. Int J Gynaecol Obstet. 1990; 33(3):203-210.

18. Zeleke BM, Zelalem M, Mohammed N. Incidence and correlates of low birth weight at a referral hospital in Northwest Ethiopia. Pan Afr Med J. 2012; 12:4.

19. Das Gupta R, Swasey K, Burrowes V, Hashan MR, Al Kibria GM. Factors associated with low birth weight in Afghanistan: a cross-sectional analysis of the demographic and health survey 2015. BMJ Open. 2019; 9(5):e025715.

20. Deshpande Jayant D, Phalke DB, Bangal VB, Peeyuusha D, Sushen B. Maternal risk factors for low birth weight neonates: a hospital based case-control study in rural area of western Maharashtra, India. NJCM. 2011; 2(3):394-398.

21. Dahlui M, Azahar N, Oche OM, Aziz NA. Risk factors for low birth weight in Nigeria: evidence from the 2013 Nigeria Demographic and Health Survey. Glob Health Action. 2016; 9:28822. 